\title{
Local climate zone approach on local and micro scales: dividing the urban open space
}

\author{
3 \\ Auline Rodler ${ }^{1,2}$ and Thomas Leduc ${ }^{3}$ \\ ${ }^{1}$ Cerema, Equipe-Projet BPE, Nantes, France \\ ${ }^{2}$ AAU-CRENAU, École Nationale Supérieure d'Architecture de \\ Nantes, Nantes, France \\ ${ }^{3}$ AAU-CRENAU, CNRS, École Nationale Supérieure \\ d'Architecture de Nantes, Nantes, France
}

March 25, 2019

\begin{abstract}
This article is a formalisation of the local climate zone (LCZ) classification on a local and micro scales. It is also an attempt to transpose this classification to a fine grained level of detail. The urban space is divided into virtual sensors for which five morphological indicators are calculated. Therefore, this work exposes a comparison of two methods dividing the urban space: the Delaunay triangulation versus a Skeletonization. These algorithms are based on a standard vector dataset and integrated in a free and open source Geographic Information System. These algorithms are applied to New York and districts of Nantes. The skeletonization presents the advantage of pulling down the calculation time without affecting the accuracy. Moreover, the methodology proposed is reproducible everywhere. In addition, the major LCZ obtained on the districts of Nantes are verified by comparison to previous measurements and classifications, which supports the results presented in this paper. Finally, the methodology and functionalities developed in this paper seem useful for the urban climate community and town planners, because LCZ can provide input data for numerical climate models that incorporate urban canopy parameters to forecast climate variables and forecast Urban heat islands (UHI).

Keywords: Urban Heat Island; Urban morphological indicators; Local climate zone; 2D GIS; Standard data; Urban skeleton
\end{abstract}

\section{Introduction}

Built up areas like cities are characterized by little vegetation and therefore a high amount of impervious surfaces with lower evaporation heat flux; a high rugosity (high buildings that can lower the wind speed); longwave radiation blocked in the streets (due to a limited sky view factor) and radiative trapping due to the city shape. These elements explain why the urban climate can differ from the rural climate (Mills 2007): temperature 
is often higher in urban central districts than in their surrounding rural areas. This observation is called the Urban heat island and has a lot of consequences. UHI can increase the mortality risk, especially during heat waves. The lack of air circulation due to the urban heat island effect can influence the dispersion of air pollutants in a metropolis (Lai 2018). UHI can affect the outdoor comfort (Morille and Musy 2017) and energy consumption (Salvati, Coch Roura, and Cecere 2015).

Solutions are proposed to mitigate the UHI and lower the air temperature in cities by:

- Increasing the albedo of materials to avoid the absorption of high amounts of solar radiation (Yu et al. 2008),

- Planting trees to create shadows and evapotranspiration (Santamouris et al. 2017),

- Covering roofs and facades with low vegetation (Musy, Malys, and Inard 2017),

- Pavement watering (Azam et al. 2018).

Urban morphology has proven to be useful to the understanding of the $\mathrm{UHI}$ and for the propagation of heat and cooling. For example, (Bernard, Rodler, et al. 2018) have highlighted that the cooling induced by a given park would better propagate within streets with a large aspect ratio (building height to street width ratio, $\mathrm{H} / \mathrm{W}$ ).

The urban's morphology influence on the air temperature distribution in a built up area can be studied through climate models using the 2D/3D geometry of the city, such as Solene-Microclimat (Musy, Malys, Morille, et al. 2015), ENVI-met ${ }^{1}$ ). or previously developed climate models (Grimmond et al. 2010). Urban climate modeling is usually performed on three scales (Tim R. Oke 2006; T. Oke 1987). On the mesoscale, a whole city can be studied, but local characteristics are parametrized and the results are obtained for homogenous cells, the dimension of which is generally $\geq 200 \mathrm{~m}$. On the local scale, a district is extracted from its context and explicitly represented, with building forms, materials, natural surfaces, etc. On the microscale, very local phenomena are represented with an accurate level of detail aiming at representing trees, urban furnitures, etc. in a particular street.

Urban classification has been proposed to split the territory according to a Local Climate Zone (LCZ) definition (I. D. Stewart and T. R. Oke 2012). A local climate zone is a region of uniform surface cover, structure, material and human activity sizing hundreds of meters to several kilometers on a horizontal scale. Each LCZ is mainly governed by building height and spacing, pervious surface fraction, tree density and soil wetness (I. D. Stewart and T. R. Oke 2012; Iain D. Stewart, T. R. Oke, and Krayenhoff 2014). Each LCZ has a characteristic screen-height temperature regime. LCZs can provide input data for numerical climate models that incorporate urban canopy parameters into their formulations to forecast the climatic conditions and UHI magnitudes. The applicability of the LCZ classification for different UHI study domains is proven by researchers (Leconte et al. 2015; Mills 2007; Perera and Emmanuel 2018; Geletič and Lehnert 2016; Kotharkar and Bagade 2018). Yet, it should be noted that a LCZ temperature difference is not an urban-rural difference.

Most of the methods to find an appropriate LCZ are based on a process. Firstly, the territory is divided in meshes, or regular grids, and the relevant

${ }^{1}$ https : //www. envi-met.com/ (Accessed February 2019). 
data is collected. Secondly, the thermal source area of the station is estimated. Thirdly, the geometric and surface cover properties are calculated within each mesh from vector databases or satellite images if provided. Finally, each mesh is linked to a LCZ. These steps have been mostly done manually (Leconte et al. 2015), but some authors propose automatic solutions (Bocher et al. 2018; Lelovics et al. 2014).

Standardized and automatic methods to calculate urban indicators and to classify the urban fabric for any city in the world is nowadays a challenge. The World Urban Database and Access Portal Tools (WUDAPT) is a community-based project with the scientific aim to classify the urban fabric (on the city scale) by climate properties from available data at on a world scale, using free satellite images and free and open-source software such as the SAGA Geographic Information System (GIS). Most of the studies using the LCZ approach classify entire cities or megalopolises and use large grids ${ }^{2}$ : WUDAPT community calculates LCZs with resolutions ranging from $300 \mathrm{~m}$ to $10 \mathrm{~km}$.

However, it is possible to study the LCZs at a finer scale (Quanz et al. 2018). For example, we know that the building density, the sky view factor and surface cover are not uniform in any LCZ, and thus temperatures fluctuate across short distances (Iain D. Stewart, T. R. Oke, and Krayenhoff 2014). Remarkable spatial variability of air temperature in a LCZ was observed during short-term observations (Leconte et al. 2015) and long-term observations (Fenner et al. 2017). The inter-LCZ differences seem to be especially pronounced at night-time and present between inner-city LCZ (Fenner et al. 2017), which leads the authors to say that the LCZ classification method should be improved to derive LCZ sub classes. These observations lead us to use the LCZ approach on smaller parts of a city. However, few works so far have investigated intra-urban LCZs.

Results are influenced by both the shape and scale of the aggregation unit, as pointed out by the Modifiable Areal Unit Problem (Openshaw 1983). Available maps generated by the Urban planning and Layouts agency for the Ile-de-France region show that the zoning is made of contiguous urban blocks surrounded by streets. Some authors (Plumejeaud-Perreau et al. 2015) raised a problem linked to this zoning method: "the produced zoning is not a continuous one: the set of cells do not build a full partition of the urban space". A solution exists, based on the union of contiguous cadastral parcels: the frontiers of islets are built so as to share in two parts the space existing between each street-block. For that purpose, some researchers in urban planning and architecture (Plumejeaud-Perreau et al. 2015; Sarradin et al. 2007) use the properties of skeleton tessellation for a balanced zoning between a set of points or 'virtual sensors'.

Finally, the main contributions of this paper are:

- First, a fine grain formalism of the LCZ classification by using 2D-GIS with standard (vector) datasets. Five indicators are implemented and the LCZ approach used. A vector database is used to transpose results into computer-aided design tools. Among the implemented indicators, the aspect ratio is improved by implementing two equations for the squares and the streets, and the sky view factors is adapted from (Bernard, Bocher, et al. 2018).

- Second, a detailed street-level implementation of five indicators such as Sky View Factor, aspect ratio, Building Surface Fraction, Impervious Surface Fraction, and Height of Roughness Elements. These five

\footnotetext{
${ }^{2}$ http: //www . wudapt .org/ (Accessed February 2019).
} 
indicators, coupled with the intervals provided by (I. D. Stewart and T. R. Oke 2012), make it possible to estimate the LCZ of the immediate environment of any sensor. By aggregation, we can deduce the LCZ on the block - or district scales.

- Third, a space meshing method to improve computation times while ensuring correlation to the LCZs found is studied. Indeed, the skeletonization of the unbuilt space allows to decimate the number of sensors, compared to a network of irregular triangles obtained by Delaunay triangulation.

- Fourth, the observation that the intervals proposed by (I. D. Stewart and T. R. Oke 2012) are not perfectly covering all the potential indicator values (insofar as they do not allow any type of fabric to be classified in one of the seventeen LCZs provided by (I. D. Stewart and T. R. Oke 2012)).

This paper is structured as follows. First, the materials and methods are presented (including the LCZ classification, the several indicators, and the global methodology implemented). Second, the results are shown on three different districts. Finally, the discussion and conclusion close the paper.

\section{Materials and methods}

\subsection{LCZ classification}

As a reminder, the LCZs are defined as "regions of uniform surface cover, structure, material, and human activity that span hundreds of meters to several kilometers in horizontal scale" (I. D. Stewart and T. R. Oke 2012). The LCZ concept classifies urban and natural environments into classes characterized by geometric, surface parameters, thermal, radiative and metabolic properties for local climate zones. Each LCZ has a specific range of these parameters and the ones used in this paper are presented in Table 1. The concept distinguishes between ten "urban" or "built-up" and seven "natural" LCZs (Fig. 1). In this paper, the thermal, radiative and metabolic properties of each urban component are not used as they are missing data. Moreover, of the seven indicators proposed by (I. D. Stewart and T. R. Oke 2012), two are not implemented for very different reasons.

- For our dataset, the terrain's roughness class does not discriminate on the chosen scale level.

- Due to the lack of availability of appropriate datasets (e.g. grassy backyards are not listed in the topographic repositories available to us), the Pervious Surface Fraction cannot be properly implemented. 

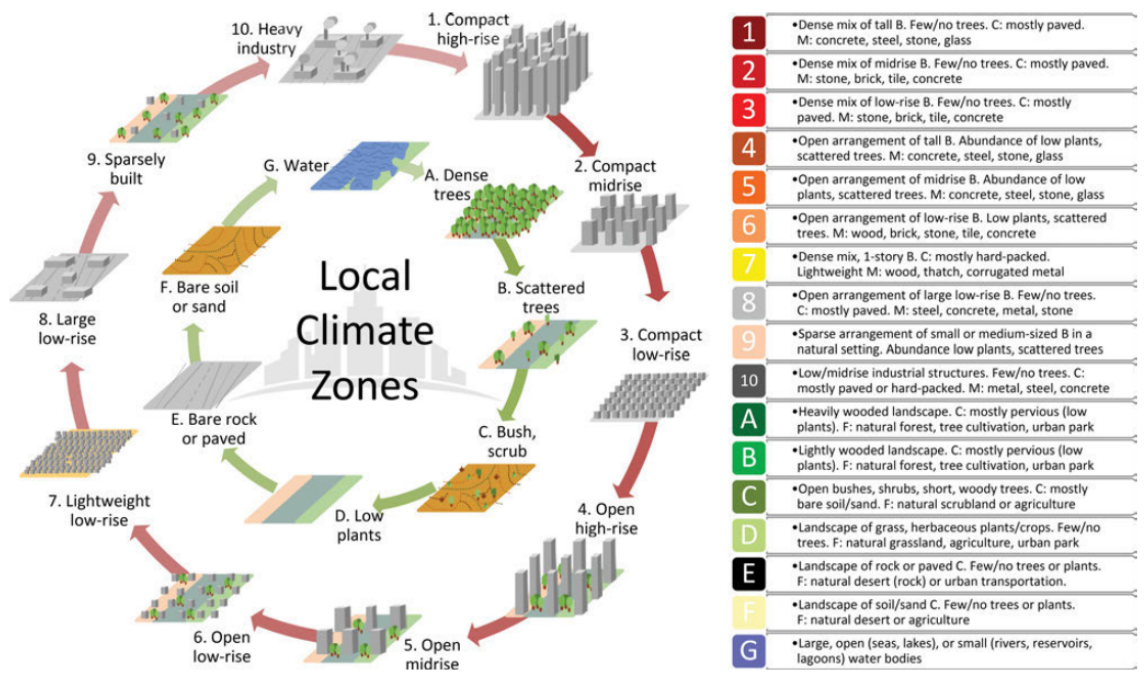

Fig. 1: Local climate zone concept with 'urban' LCZ (1-10) and 'natural' LCZ (A-G); icons reworked. B: buildings, C: cover, M: materials, F: function, tall: $>10$ stories, mid-rise: 3-9 stories, low: 1-3 stories. Figure taken from (Bechtel et al. 2017). 
Table 1: Values of geometric and surface cover properties for local climate zones. All properties are unit-less except the height of roughness elements (meters) (I. D. Stewart and T. R. Oke 2012).

\begin{tabular}{|c|c|c|c|c|c|}
\hline $\begin{array}{l}\text { Local Climate Zone } \\
\text { (LCZ) }\end{array}$ & $\begin{array}{l}\text { Sky view } \\
\text { Factor }\end{array}$ & $\begin{array}{c}\text { Aspect } \\
\text { Ratio }\end{array}$ & $\begin{array}{l}\text { Building } \\
\text { surface } \\
\text { fraction }\end{array}$ & $\begin{array}{c}\text { Impervious } \\
\text { surface } \\
\text { fraction }\end{array}$ & $\begin{array}{c}\text { Height of } \\
\text { roughness } \\
\text { elements }\end{array}$ \\
\hline $\begin{array}{l}\text { LCZ } 1 \\
\text { Compact high-rise }\end{array}$ & $0.2-0.4$ & $>2$ & $40-60$ & $40-60$ & $>25$ \\
\hline $\begin{array}{l}\text { LCZ } 2 \\
\text { Compact midrise }\end{array}$ & $0.3-0.6$ & $0.75-2$ & $40-70$ & $30-50$ & $10-25$ \\
\hline $\begin{array}{l}\text { LCZ } 3 \\
\text { Compact low-rise }\end{array}$ & $0.2-0.6$ & $0.75-1.5$ & $40-70$ & $20-50$ & $3-10$ \\
\hline $\begin{array}{l}\text { LCZ } 4 \\
\text { Open high-rise }\end{array}$ & $0.5-0.7$ & $0.75-1.25$ & $20-40$ & $30-40$ & $>25$ \\
\hline $\begin{array}{l}\text { LCZ } 5 \\
\text { Open midrise }\end{array}$ & $0.5-0.8$ & $0.3-0.75$ & $20-40$ & $30-50$ & $10-25$ \\
\hline $\begin{array}{l}\text { LCZ } 6 \\
\text { Open low-rise }\end{array}$ & $0.6-0.9$ & $0.3-0.75$ & $20-40$ & $20-50$ & $3-10$ \\
\hline $\begin{array}{l}\text { LCZ } 7 \\
\text { Lightweight low-rise }\end{array}$ & $0.2-0.5$ & $1-2$ & $60-90$ & $<20$ & $2-4$ \\
\hline $\begin{array}{l}\text { LCZ } 8 \\
\text { Large low-rise }\end{array}$ & $>0.7$ & $0.1-0.3$ & $30-50$ & $40-50$ & $3-10$ \\
\hline $\begin{array}{l}\text { LCZ } 9 \\
\text { Sparsely built }\end{array}$ & $>0.8$ & $0.1-0.25$ & $10-20$ & $<20$ & $3-10$ \\
\hline $\begin{array}{l}\text { LCZ } 10 \\
\text { Heavy industry }\end{array}$ & $0.6-0.9$ & $0.2-0.5$ & $20-30$ & $20-40$ & $5-15$ \\
\hline $\begin{array}{l}\mathrm{LCZ} \text { A } \\
\text { Dense trees }\end{array}$ & $<0.4$ & $>1$ & $<10$ & $<10$ & $3-30$ \\
\hline $\begin{array}{l}\text { LCZ B } \\
\text { Scattered trees }\end{array}$ & $0.5-0.8$ & $0.25-0.75$ & $<10$ & $<10$ & $3-15$ \\
\hline $\begin{array}{l}\text { LCZ C } \\
\text { Bush, scrub }\end{array}$ & $0.7-0.9$ & $0.25-1$ & $<10$ & $<10$ & $<2$ \\
\hline $\begin{array}{l}\text { LCZ D } \\
\text { Low plants }\end{array}$ & $>0.9$ & $<0.1$ & $<10$ & $<10$ & $<1$ \\
\hline $\begin{array}{l}\mathrm{LCZ} \mathrm{E} \\
\text { Bare rock or paved }\end{array}$ & $>0.9$ & $<0.1$ & $<10$ & $>90$ & $<0.25$ \\
\hline $\begin{array}{l}\text { LCZ F } \\
\text { Bare soil or sand }\end{array}$ & $>0.9$ & $<0.1$ & $<10$ & $<10$ & $<0.25$ \\
\hline $\begin{array}{l}\text { LCZ G } \\
\text { Water }\end{array}$ & $>0.9$ & $<0.1$ & $<10$ & $<10$ & - \\
\hline
\end{tabular}

\subsection{Data sources}

For reasons of replicability, we have decided to use standard topographic datasets and software. To guarantee this deliberate choice, we have identified the European INSPIRE directive for the two sites we have selected in France. This Directive, which entered into force on 15 May 2007, aims to create a European Union spatial data infrastructure to facilitate and promote EU policies and activities that may have an impact on the environment.

For the French case, the BD TOPO® database, which is a $3 \mathrm{D}$ vectorial description (structured in objects) of the elements of the territory and its infrastructures, of metric precision, usable on scales ranging from 1:5,000 to 1:50,000, complies with the recommendations of the INSPIRE directive.

This topographic database, which consistently covers the entire national territory, is made available by the IGN. Its data and technical specifications 
are published and available online ${ }^{3}$.

In order to test and validate our approach with a non-European dataset, we have identified an urban fragment on the North American territory. The planimetric dataset available for free for the NYC OpenData portal seemed to us to be the most immediately usable. This data is derived from the imaging products delivered with the New York State Overview in 2014. It includes a set of polygonal building footprints representing the perimeter contour of each building. These geometries are completed with attributes such as the height of the roof above the ground elevation. Corresponding data and technical specifications are published and available online ${ }^{4}$. Concerning the geometry of the street network, we use polylines from the New York Citywide Street Centerline database, a single line representation of New York City streets. Corresponding data and technical specifications are published and available online ${ }^{5}$.

To test this new approach, we have selected three case studies with very different morphologies, presenting various architectural styles. The aim was also to test different types of datasets, in order to have a more robust method. The first is a typical urban configuration of a North American city with contemporary architecture. It is an area of about 73.7 ha located in Borough Park, Brooklyn, New York $\left(40.7128^{\circ} \mathrm{N}, 74.0060^{\circ} \mathrm{W}\right)$. The second and third cases are located in Nantes $\left(47.2184^{\circ} \mathrm{N}, 1.5536^{\circ} \mathrm{W}\right)$, a mediumsized city in the west of France. The second case (which we call the "Royale district") is an urban centre of about 11.3 ha composed of a homogeneous set of buildings that reflect the classical architecture of the $18^{\text {th }}$ and $19^{\text {th }}$ centuries. The third case (which we call "Méthode district") is a residential area of intermediate density. It is a mixed sector of about $12.7 \mathrm{ha}$, composed of single-family homes, as well as large housing buildings.

\subsection{Implementation of urban indicators: geometric and surface cover properties}

For the determination of the LCZs, we have chosen to evaluate the several indicators mentioned in Table 1 in a set of points that we call "virtual sensors". The objective of this section is to present the details of the implementation of indicators by first introducing some key concepts. We will be concerned with the location of these virtual sensors in the next section.

\subsubsection{Prerequisites: delimit the boundaries of the immediate sur- roundings}

Lets consider a virtual sensor (represented by a red dot on Fig. 2, Fig. 3, and Fig. 7). In order to calculate the above-mentioned indicators at this point, we start by introducing two different methods for determining the immediate environment of the corresponding position.

The first method, very classic, is a circular buffer, whose radius length is arbitrarily chosen (see Fig. 2a). It can be estimated that, because it does not take into account the presence of possible masks in the area (masks likely to alter the physical phenomenon under study), this buffer characterizes isotropic phenomena, i.e. identically distributed in all directions of space.

\footnotetext{
${ }^{3}$ At http://professionnels.ign.fr/bdtopo (Accessed February 2019).

${ }^{4}$ At https://github.com/CityOfNewYork/nyc-geo-metadata/blob/master/Metadata/ Metadata_BuildingFootprints.md (Accessed February 2019).

${ }^{5}$ At https://github.com/CityOfNewYork/nyc-geo-metadata/blob/master/Metadata/ Metadata_StreetCenterline.md (Accessed February 2019).
} 
The second method, less frequently used, is called the isovist, a notion that has been theorized by (Benedikt 1979). It corresponds to all the points of the plane directly "visible" from a given location, in all directions (it is a panoptic feature), integrating the notion of "mask", such as built masks for example (see Fig. 2b). In outdoor spaces, the isovist is almost systematically associated with an artificial horizon, which prevents "the rays from starting infinitely" (see Fig. 2b, the western part of the isovist is truncated by the circular buffer of a $200 \mathrm{~m}$ radius assimilated to an artificial horizon). With a standard topographic dataset, this isovist is a polygonal surface in a horizontal plane. It is very useful to define and qualify the open space that immediately surrounds the observation/generation point.

The immediate environment of the virtual sensor having been defined, we introduce a second tool in order to be able to characterize it. This is a transposition of the ray-casting mechanism to the GIS context (see Fig. 3a). This involves launching a set of rays, equidistributed in all directions of the plane (which implies that the pitch of the corresponding angular abscissa is $\left.\frac{2 \pi}{\mathrm{nRays}}\right)$. For a given direction, the corresponding radius strikes a group of buildings. Depending on the indicator chosen, we can either select the pair (h[i], w[i]) corresponding to the smallest w[i] (this is the solution used to calculate the aspect ratio) or the pair $(\mathrm{h}[\mathrm{i}], \mathrm{w}[\mathrm{i}])$ that maximizes the ratio $\frac{\mathrm{h}[\mathrm{i}]}{\mathrm{w}[\mathrm{i}]}$ (this is the solution used to calculate the sky view factor), as shown in Fig. 3b.
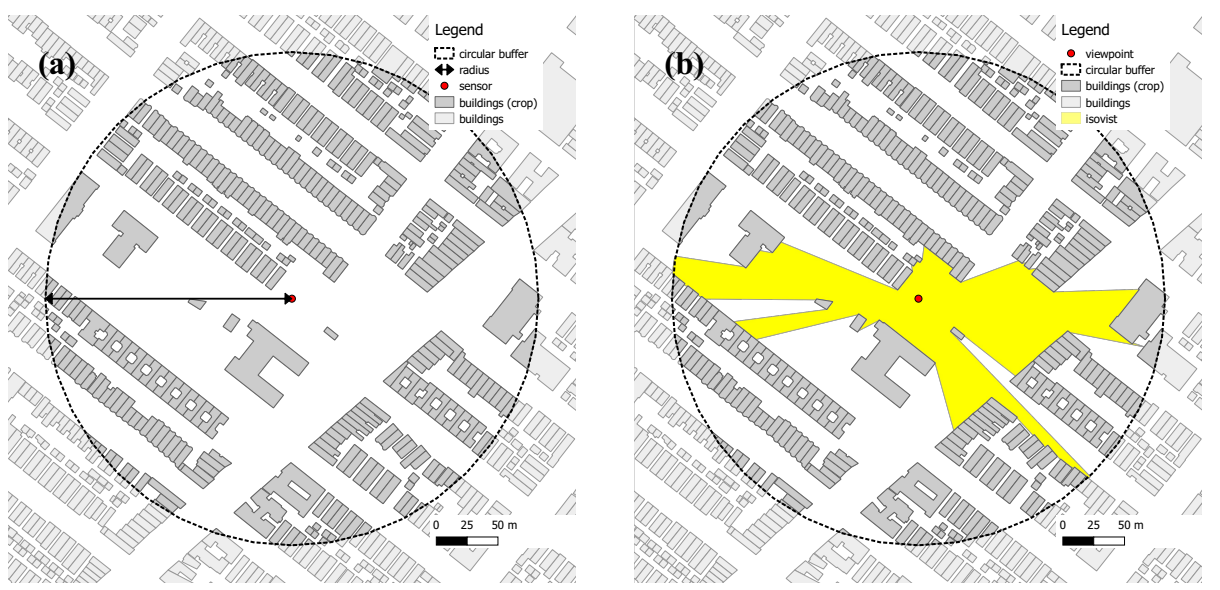

Fig. 2: Two different methods of delineating surrounding spaces: (a) Circular buffer. (b) Isovist. 

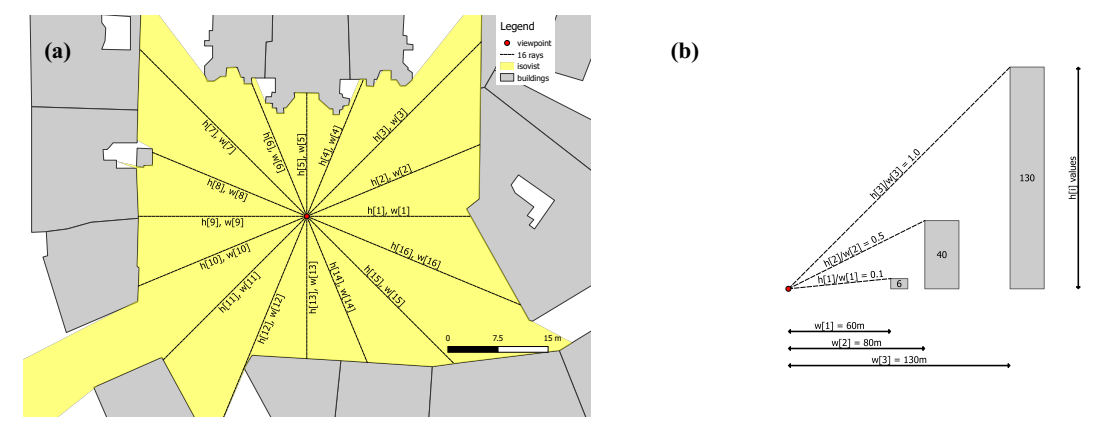

Fig. 3: (a) Ray cast strategy: Set of rays casted from a given position with corresponding $\mathrm{w}[\mathrm{k}]$ (ray length from the position to the hitting point on building) and $\mathrm{h}[\mathrm{k}]$ (building height) attributes. Buildings elevations are inscribed in the corresponding building's footprints. (b) For a given direction, the corresponding radius strikes a group of buildings. Depending on the indicator chosen, we can either select the pair $(\mathrm{h}[\mathrm{i}], \mathrm{w}[\mathrm{i}])$ corresponding to the smallest $\mathrm{w}[\mathrm{i}]$ or the pair $(\mathrm{h}[\mathrm{i}], \mathrm{w}[\mathrm{i}])$ that maximizes the ratio $\frac{\mathrm{h}[\mathrm{i}]}{\mathrm{w}[\mathrm{i}]}$.

\subsubsection{Sky view factor (SVF)}

The sky view factor is an indicator of the amount of sky vault visible from the ground at a given position, i.e. the proportion of sky not obstructed by the surrounding built masks. Several calculation methods exist based on the analysis of fisheye-lens photographs (Steyn 1980), empirical laws on simplified street models (Johnson and Watson 1984), double projection mechanisms and sky opening maps (Teller and Azar 2001), digital vector approaches (Souza, Rodrigues, and Mendes 2003), and raster-based approaches (Gál, Lindberg, and Unger 2009).

Because our case studies are urban fragments of a few hundred square meters and because we need an inframetric resolution (as we will see later in the section dedicated to partitioning the unbuilt space), we have opted for a vector implementation of the SVF by adapting (Bernard, Bocher, et al. 2018). This approach has the advantage of being more precise than rasterbased implementations and not dependent on the way the selected space is divided.

Lets consider $(r, \theta, \varphi)$ the spherical coordinates of a given point, where $r$ is the Euclidean radial distance to the origin, $\theta$ is the latitude to the equator plane, and $\phi$ is the azimuthal angle (longitude) starting from east. With these notations, the spherical surface element ranging from $\theta$ to $\theta+d \theta$ and from $\varphi$ to $\varphi+d \varphi$ on a spherical surface at constant radius $r$ is:

$$
d^{2} S=r^{2} \cos (\theta) d \theta d \varphi
$$

And the corresponding differential solid angle is equal to:

$$
d \Omega=\cos (\theta) d \theta d \varphi
$$

If we integrate this differential solid angle on the spherical surface in red in Fig. 4a, we obtain the following equation (after dividing the hemisphere equally into slices by rotation angle $\frac{2 \pi}{\text { nRays }}$ ):

$$
\Omega_{i}=\int_{\varphi=0}^{\frac{2 \pi}{\mathrm{nRays}}} \int_{\theta=0}^{\arctan \left(\frac{H_{i}}{W_{i}}\right)} \cos (\theta) d \theta d \varphi=\frac{2 \pi \times \sin \left(\arctan \left(\frac{H_{i}}{W_{i}}\right)\right)}{\text { nRays }}
$$


In the case of Fig. $4 \mathrm{~b}$, the ratio of visible sky divided by the surface of a unit hemisphere $(2 \pi \mathrm{sr})$ is therefore equal to the complementary to the sum of the solid angles of the various surrounding built masks and equal to:

$$
\mathrm{SVF}=\frac{2 \pi-\sum_{i=0}^{\mathrm{nRays}} \Omega_{i}}{2 \pi}=1-\frac{1}{\text { nRays }} \sum_{i=1}^{\text {nRays }} \sin \left(\arctan \left(\frac{H_{i}}{W_{i}}\right)\right)
$$
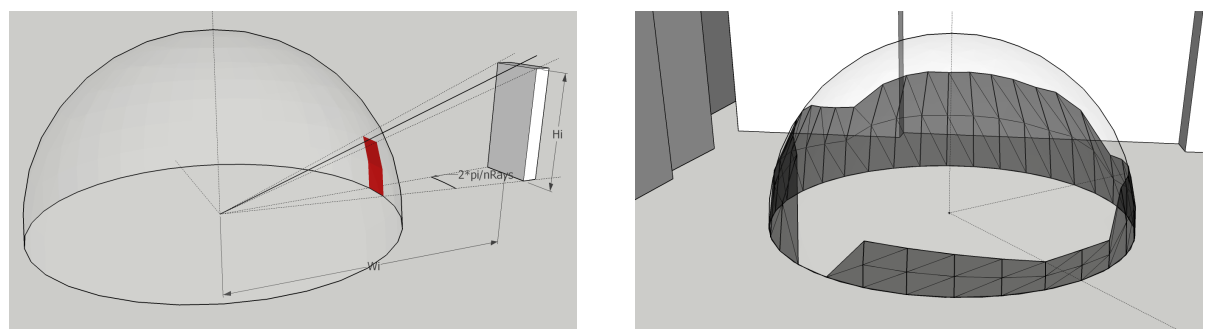

Fig. 4: (a) The solid angle of the built mask of height $H_{i}$, angular deviation $\frac{2 \pi}{\text { nRays }}$, located at the distance $W_{i}$ from the point of view is equal to $\frac{2 \pi}{\text { nRays }} \sin \left(\arctan \left(\frac{H_{i}}{W_{i}}\right)\right)$. (b) The sky view factor is the ratio of the amount of the sky hemisphere visible from the ground to that of an unobstructed hemisphere.

As mentioned in the previous section, in the specific context of the evaluation of the SVF, in order to calculate the solid angle of the built mask represented in Fig. 4a, we select the pair (h[i], w[i]) that maximizes the ratio $\frac{\mathrm{h}[\mathrm{i}]}{\mathrm{w}[\mathrm{i}]}$ (see Fig. 3b).

\subsubsection{Aspect ratio $(\mathrm{H} / \mathrm{W})$}

In the simplified city model developed by (T. Oke 1988), the street canyon is the basic geometric unit that allows, by simple repetition, to approximate the urban fragment studied. If we make the (strong) assumption that the buildings flanking this street canyon are infinite in length, then this model can be simplified by a two-dimensional cross-section. This very simplified configuration makes it possible to introduce $h / w$ the aspect ratio, as the ratio of the average height of the canyon walls $(h)$ to the width of the canyon (w).

We propose to extend this definition to squares and other open spaces that are clearly not comparable to canyons. To this end, and provided that we are able to discriminate between urban canyons and other open spaces, we use the aforementioned ray casting method. When the viewpoint is located in a street canyon, a pair of "directional" rays are casted towards the nearest buildings. On the other hand, when the viewpoint is located in a space that is not considered a street canyon, a collection of panoptic rays (equidistributed in all directions of the plane) is casted. Indeed, in the case of a more widely open space, no main orientation can be easily identified in contrast with the case of canyon street. This dual implementation is shown in Fig. 5. The following formula is a generalization of the aspect ratio that is valid in both cases.

$$
\text { aspect ratio }=\frac{\frac{1}{\mathrm{nRays}} \sum_{i=0}^{\mathrm{nRays}} h_{i}}{\frac{1}{\mathrm{n} \text { Rays }} \sum_{i=0}^{\mathrm{nRays}} 2 \times w_{i}}=\frac{\bar{h}}{2 \times \bar{w}}
$$




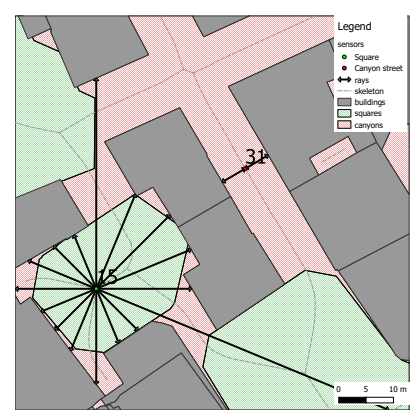

Fig. 5: To calculate the aspect ratio, we use two different methods, depending on the position of the sensor. When located in a canyon street (point \#31), the ray cast is "directional" (meaning that it is thrown towards the nearest building). When the sensor is located in a square (point \#15), the ray cast is panoptic.

To detect and identify the squares and canyon streets, the traditional dilation-erosion technique is adopted. The first step consists in homogeneous dilation (uniform expansion in all directions of the plane) of all building footprints using the same arbitrarily fixed buffering distance. This enlargement is followed by a spatial union that allows for fusion of nearby building footprints (see Fig. 6a). The next step is to apply homothetic reduction to all the extended building footprints resulting from the previous space union. These "eroded" built spaces are then subtracted from the study area to delineate so-called "squares" or large open spaces. These urban squares are the result of a fourfold process of dilation, merging, erosion and subtraction (see Fig. 6b). Once the squares have been identified, the final step is to delineate the urban canyons. It is a two-step operation. By subtracting the buildings from the study area, we obtain all open or unbuilt spaces (like some sort of photochemical negative in the silver photographic transform). All that remains is then to remove the several squares identified in the previous step to delineate the streets canyons (Fig. 6c).

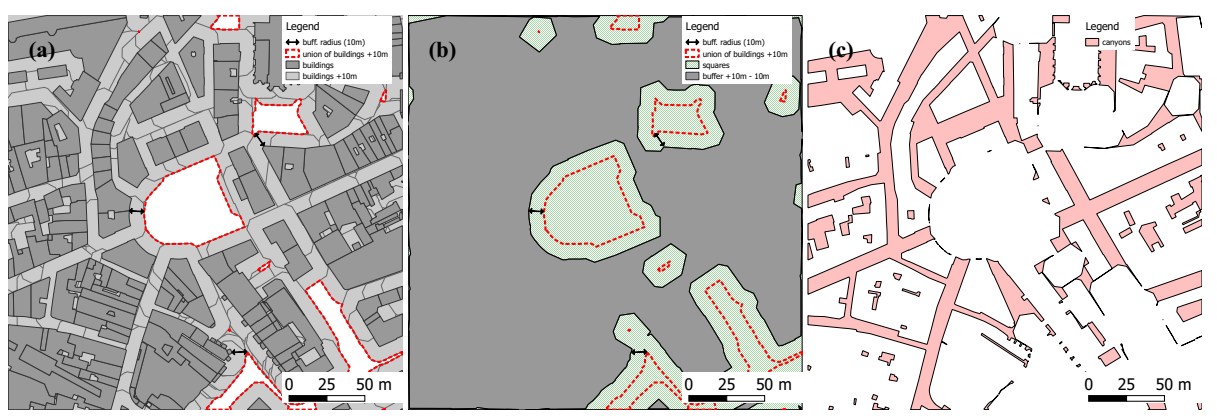

Fig. 6: Use of a dilation-erosion technique for the automatic detection of canyon streets and squares. In this example, the street width parameter is arbitrarily set to $10 \mathrm{~m}$. (a) Buildings dilation, street canyons disappear. (b) Erosion of "extended" buildings (by spatial union), squares identification. (c) Identification of canyon streets (by subtracting squares from all open spaces). 
Fig. 7: Systematic application of a buffer on road centerlines (the "st_width" buffering distance varies from $8 \mathrm{ft}$, to 30 , and even 48 on the main road).

The building surface fraction is a dimensionless indicator that represents, for a given reference area, the ratio of built area. To calculate it, we start by adding the areas of the different building footprints (or portions of building footprints) included in the circular buffer area shown in Fig. 2a. The BSF is equal to the ratio of this cumulative area divided by the disk area of the circular buffer mentioned above.

\subsubsection{Impervious surface fraction (ISF)}

To calculate the impervious surface fraction, we must first reconstruct the shape of the impervious cover as accurately as possible. This reconstruction is the result of a homothetic dilation of the road centerlines provided by input datasets. It also depends on the width of each road segment. Which is an attribute of the corresponding layer (namely "LARGEUR" within the BD TOPO ${ }^{\circledR}$, and "st_width" within the New York Citywide Street Centerline database). Fig. 7 shows an application of this virtual reconstruction of the road surface in the case of New York terrain.

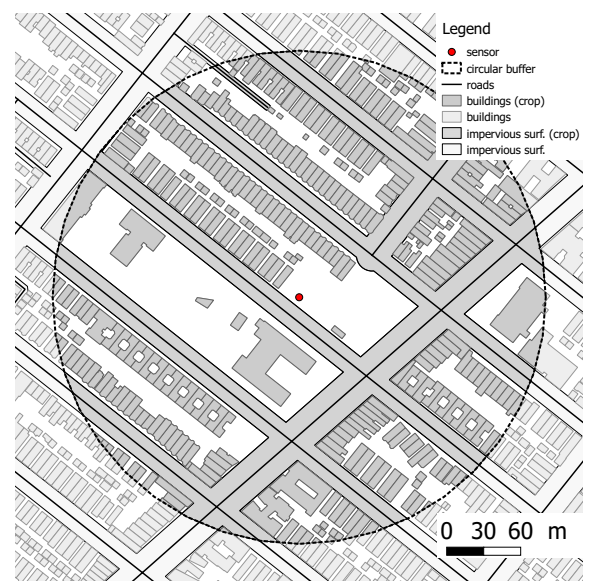

\subsubsection{Height of roughness elements (HRE)}

The height of roughness elements or absolute roughness is the mean height of the urban canopy. For a given reference area (the circular buffer shown in Fig. 2a), it is equal to the sum of the surfaces of the building footprints (or portions of building footprints) included in the reference zone, multiplied by the respective building heights and divided by the total reference area.

\subsection{Positioning of sensors}

Our objective is to qualify the LCZ at any point on the ground, based on the calculation of the various morphological indicators mentioned above, and, by grouping these elementary units contiguously, to define uniform subdivisions - in the climatic sense - of space. The study space (which is

\subsubsection{Building surface fraction (BSF)}


limited to urban open spaces only) being continuous, the first step consists in its discretization. Several solutions exist, such as, for example, a regular grid of the space (Fig. 8a), a Delaunay triangulation of the space (Fig. 8b), or a skeletonization of the space (Fig. 8c).

The regular grid is presented as it is still used in some approaches. The drawback with this grid is that it is unsuitable for a real city geometry and favours cardinal orientations. A regular grid does not accurately represent a sloped surface unless it is meshed very thinly. For this reason the calculations will not be undertaken on the regular grid.

If the triangulation discretization approach has the advantage of being perfectly covering, it must be noted that it excessively multiplies the number of triangles and, consequently, of virtual sensors. The third approach by open space skeletonization is a repetition of a technique commonly used in shape analysis (from cartographic generalization to optical character recognition). The technique used is derived from the Voronoi diagram. It allows, by dimensional reduction, to cover the shape in its complexity with a small number of virtual sensors (these sensors being derived from the discretization by curvilinear abscissa of the skeleton). The question that arises, however, is the relevance of this alternative proposal in the sense of LCZs zoning.

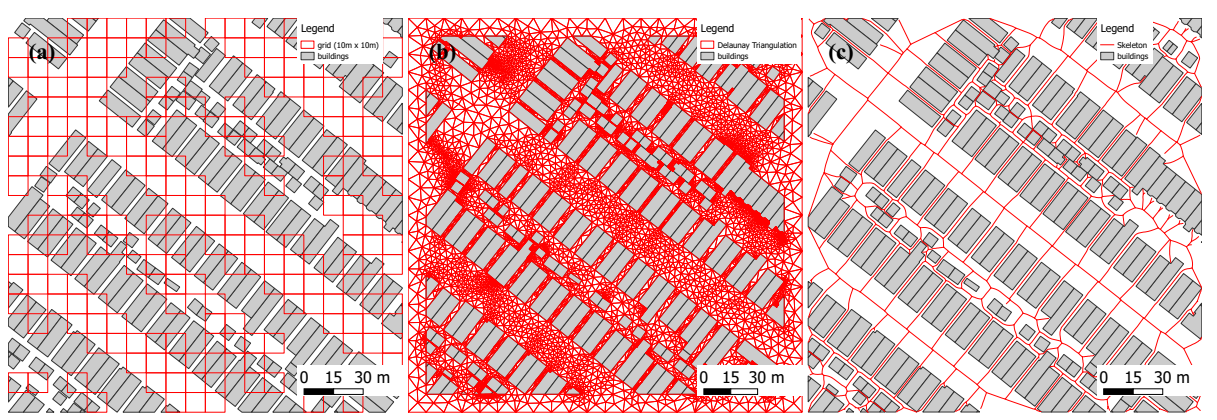

Fig. 8: Three different methods of dividing space: (a) Regular grid (217 cells). (b) Triangulated Irregular Network (TIN) based on a constrained Delaunay Triangulation (11,288 triangles). (c) Skeleton (defined as the set of centers of all maximal disks inscribed in the non-built space, cumulative length of 4,6 km).

\subsection{LCZs match-making}

\subsubsection{Nearest neighbour}

To study the validity of the skeleton-based approach, we will compare the LCZ zoning resulting from triangulation (exhaustive coverage of space) with the zoning associated with the skeleton. It is a two-step process. The first consists in match-making, through a spatial joint to the nearest neighbour, each virtual sensor associated with triangulation to the nearest virtual sensor resulting from skeleton sampling. This grouping having been carried out, we proceed to an average calculation in a second step. Indicator by indicator and by grouping sensors from triangulation (associated with the same skeleton sensor), we perform an arithmetic average. The LCZ associated with the sensor group is the one deduced from Table 1 using these different average values. 


\subsubsection{Major, minor, and LCZ determination}

Whether it is to assign a LCZ class to a virtual sensor from the Delaunay triangulation, a virtual sensor from skeletonization, or a "medium" virtual sensor representing a group of virtual sensors (cf. the nearest neighbour process described before), the process is identical.

It seems nearly impossible to find for each sensor a LCZ, and often not only one LCZ is found. That is why subclasses among the LCZs can be proposed (I. D. Stewart and T. R. Oke 2012). To apply the same data processing on all sensors, an algorithm to find the major and minor LCZs is proposed and adopted here. The LCZ attribute associated with each virtual sensor is similar to a collection of labels, where each label is a two-letter word composed of a "major" and a "minor". The major one, which is the first letter of the word, corresponds to a strong determination (5 out of 5 indicators belong to the associated LCZ, as defined in Table 1). The minor, which is the second letter of the word, corresponds to a weak determination (only 4 of the 5 indicators belong to the associated LCZ as defined in Table 1).

In the case of the Nantes - Royale application that we will present in the following article, 9 sensors (out of 15,316) are labelled "02\#03" in terms of LCZ. This label shows that, for these sensors, there is no strong determination ( 0 as a major), but that, on the other hand, two weak determinations are possible. Therefore, these sensors belong to classes 2 and 3 alike. We can consider that they are positioned at some sort of transition points. The sharp sign separates several identified LCZs having the same weight for a given sensor.

\subsubsection{LCZ matching in details}

Lets consider $\mathrm{LCZ}_{1}$ and $\mathrm{LCZ}_{2}$ be two labels (collection of labels or of 2character words) to match. Lets note $M_{1}$ (respectively $M_{2}$ ) the set of majors of $\mathrm{LCZ}_{1}$ (respectively $\mathrm{LCZ}_{2}$ ) and $m_{1}$ (respectively $m_{2}$ ) the set of minors of $\mathrm{LCZ}_{1}$ (respectively $\mathrm{LCZ}_{2}$ ), then:

$$
\mathrm{LCZ}_{1}=\left(M_{1}, m_{1}\right)
$$

and

$$
\mathrm{LCZ}_{2}=\left(M_{2}, m_{2}\right)
$$

With this encoding, the LCZ of label "02\#03" is written: $\operatorname{LCZ}_{02 \# 03}=(\{\},\{2,3\})$. The indeterminacy character " 0 " is not transcribed.

Table 2 lists a similarity measure for each given LCZ encoding pair. The larger the confidence index is and the closer the encodings are; the weaker it is and the more the encodings differ. This measure of similarity is renamed the "confidence index". 
Table 2: Values of the confidence index as a function of LCZs. The instructions in this table are to be processed in order (starting from the first line to the default condition on the last line).

\begin{tabular}{clc}
\hline \#Rule & Condition for the comparison of $\mathbf{L C Z} \mathbf{Z}_{1}$ and $\mathbf{L C Z} \mathbf{Z}_{\mathbf{2}}$ & Confidence index \\
\hline 1 & $M_{1}=M_{2}$ and $m_{1}=m_{2}$ & $100 \%$ \\
2 & $M_{1} \cup m_{1}=M_{2} \cup m_{2}$ & $80 \%$ \\
3 & $M_{1}=M_{2}$ and $m_{1} \subset m_{2}$ and $m_{1} \neq\{\}$ & $70 \%$ \\
4 & $M_{1}=M_{2}$ and $m_{2} \subset m_{1}$ and $m_{2} \neq\{\}$ & $70 \%$ \\
5 & $M_{1}=M_{2}$ and $m_{1} \cap m_{2} \neq\{\}$ & $60 \%$ \\
6 & $\left(M_{1} \cup m_{1}\right) \subset\left(M_{2} \cup m_{2}\right)$ and $\left(M_{1} \cup m_{1}\right) \cap\left(M_{2} \cup m_{2}\right) \neq\{\}$ & $50 \%$ \\
7 & $\left(M_{2} \cup m_{2}\right) \subset\left(M_{1} \cup m_{1}\right)$ and $\left(M_{1} \cup m_{1}\right) \cap\left(M_{2} \cup m_{2}\right) \neq\{\}$ & $50 \%$ \\
8 & $M_{1}=M_{2}$ & $30 \%$ \\
9 & $M_{1} \cap M_{2} \neq\{\}$ and $m_{1}=m_{2}$ & $20 \%$ \\
10 & $m_{1}=m_{2}$ & $10 \%$ \\
11 & $\ldots$ & $0 \%$ \\
\hline
\end{tabular}

For example, according to rule number 7 , the confidence index associated with the comparison of the labels "02\#03" and "30" is 50\%.

\subsection{Methodology}

The workflow presented in Fig. 9 is the one we implemented. It is divided into three groups of tasks: those related to pre-processing, those related to processing and finally those related to post-processing. The main core of this workflow corresponds to tasks labelled from 2 to 10. As may be noticed, this main core is branched to tasks 4 and 6 on the one hand, and 5 and 7 on the other. In fact, the objective is to study the influence of the sampling solution (Delaunay triangulation vs. Skeletonization) on the accuracy of LCZs found and the respective calculation times. Therefore, a sensitivity study to the "sampler" was undertaken. We adopted the most common approach, that is, changing one-factor-at-a-time and evaluating the induced effect on the output.

\subsubsection{Preprocessing (tasks 1, 2, 3, and 8)}

The purpose of the preprocessing phase is to prepare: a) the calculation of the aspect ratio indicator (task 1$), b$ ) the determination of the study area that we will sample in order to position the indicators (tasks 2 and 3), and c) the calculation of the Impervious Surface Fraction indicator (task 8).

In the first case, we distinguish street canyons from other open spaces using a dilation-erosion method already mentioned (task 1 ). In the second case (task 2), we first produce the open space to be studied by subtracting building footprints from the entire study area (also called the region of interest, roi). Then, the objective of task 3 is to simplify the contours of this potentially complex geometric shape. Finally, in the third case, we delineate road surfaces (impervious) by dilating the road centerlines (task 8).

\subsubsection{Processing (tasks 4, 5, 6, 7, and 9)}

Two concurrent sets of tasks structure the processing. The first aims to sample the open space under study from its skeleton. Therefore, task 
4 allows to produce this skeleton using a Voronoi diagram. Task 6 generates the collection of virtual sensors resulting from curvilinear abscissa sampling of the polyline corresponding to the skeleton.

The second group of tasks aims to sample the open space under study from a network of irregular triangles. Therefore, task 5 is responsible for producing this network using a Delaunay triangulation, while task 7 consists of identifying all the associated virtual sensors (as centroids of the mesh items).

Finally, task 9 is the one that, for the two sets of virtual sensors resulting from tasks 6 and 7 , is dedicated to the calculation of the 5 indicators already presented and the resulting LCZ classification.

\subsubsection{Post-processing (task 10)}

Post-processing is summarized in task 10. It consists of a) a spatial joint to the nearest neighbour (triangulation sensors are associated with the nearest sensor from the skeletonization), b) an average, indicator by indicator, for each group of triangulation sensors associated with the same closest sensor from the skeletonization, c) a matching of the LCZ from the average with the LCZ calculated at the skeleton sensor. 


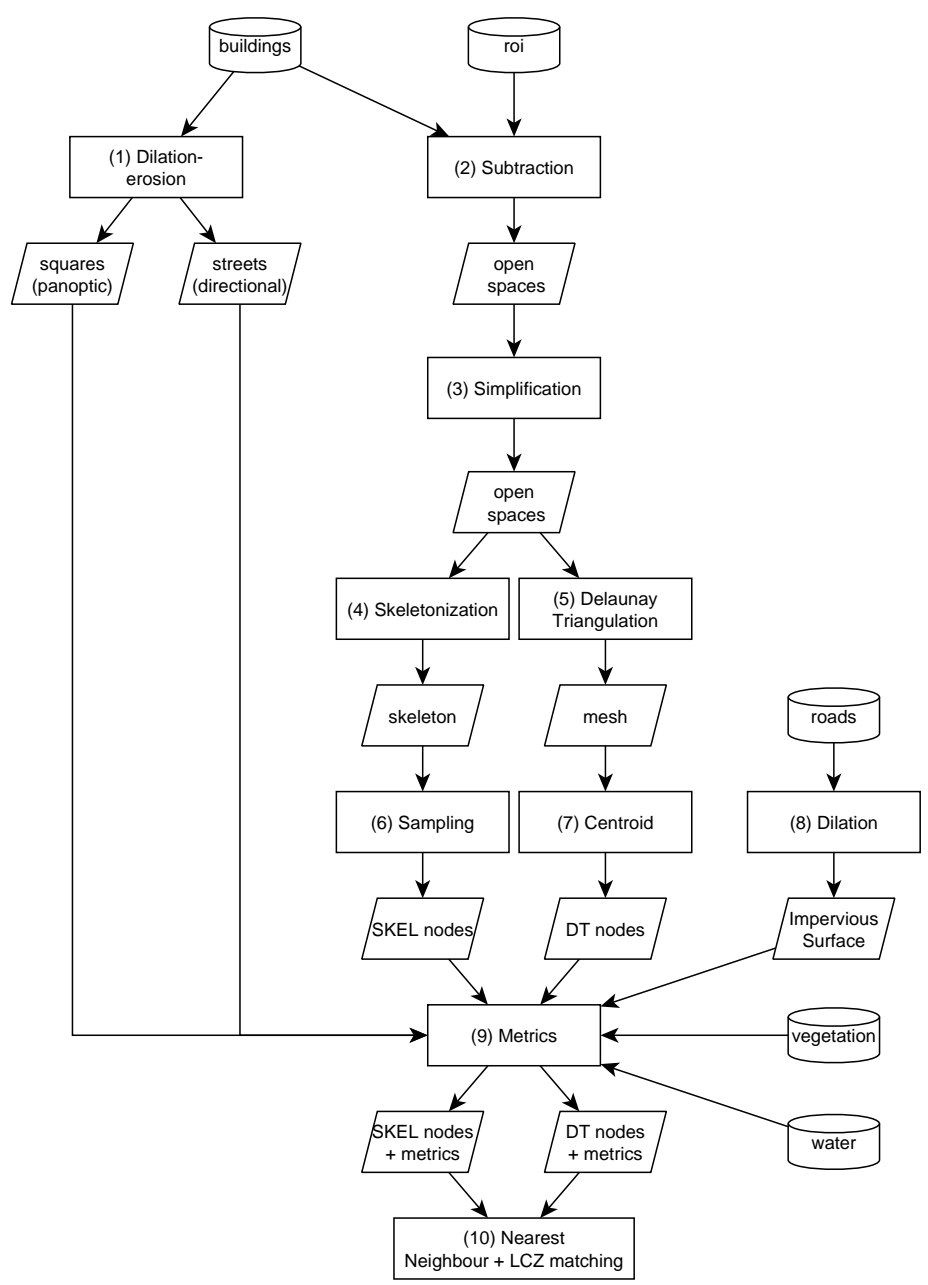

Fig. 9: The workflow implemented.

\section{Results}

In this section, three sensitivity studies are successively presented. The first concerns sensitivity to radius length. The second concerns the sensitivity to the number of rays used in the ray throwing mechanism. The third is a kind of sensitivity study of the type of sampling chosen. The number of variables and the related combinatorics being significant, we have arbitrarily chosen to present the most significant results. It should also be noted that the sensitivity studies presented in this section are a function of the spatial configuration of the selected urban fragments.

\subsection{Influence of radius length}

A sensitivity analysis has been undertaken to know what impact the chosen radius length has on the accuracy of the sky view factor, the aspect 
ratio, the building surface fraction, the impervious surface fraction, and the height of roughness elements (Fig. 10). Three radius were chosen: $50 \mathrm{~m}$, $100 \mathrm{~m}$ and $200 \mathrm{~m}$. We can see on all districts that taking $100 \mathrm{~m}$ seems to be satisfactory on all calculated indicators: the median value is very close to the one obtained with a $200 \mathrm{~m}$ radius and the outliers are not too distant from the median, as with a $50 \mathrm{~m}$ radius.

The only indicator which is not influenced by the radius is the aspect ratio. It is quite easy to understand: the street width is most of the time not larger than $20 \mathrm{~m}$ so the first radius of $50 \mathrm{~m}$ already encompasses the street width and allows to hit the first built front. Therefore, the aspect ratio defined as the ratio between the height of the building and the street width will not change for these three radius.

The results presented in the following sections are all obtained with a $100 \mathrm{~m}$ radius, which seemed to be a good compromise. Indeed, our objective is not to reproduce a large-scale approach like the WUDAPT method, but to limit the range of the radius. 

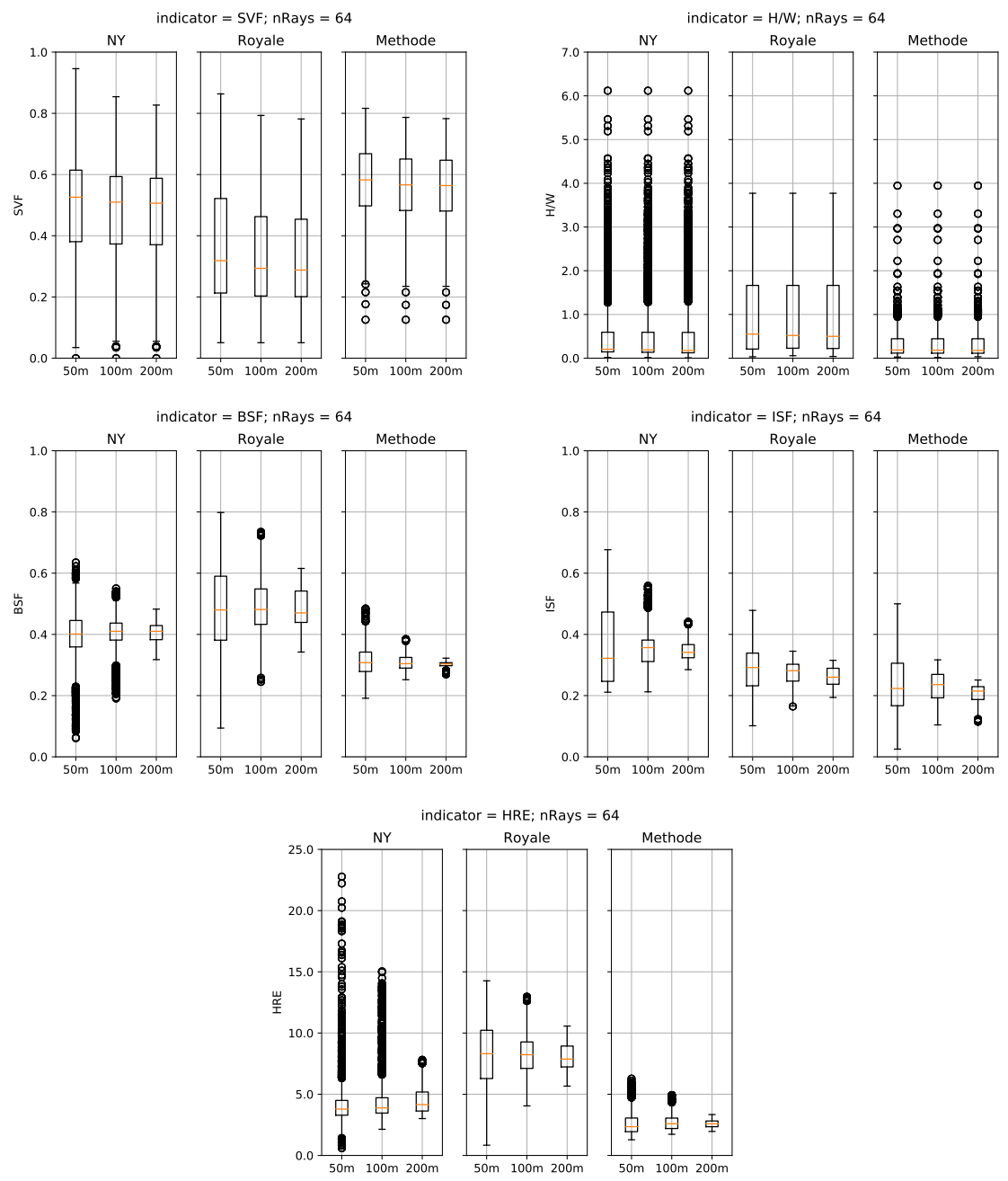

Fig. 10: Influence of the radius length on SVF, H/W, BSF, ISF, and HRE indicators, the number of rays being fixed at 64 .

\subsection{Influence of the number of rays}

A sensitivity analysis has been undertaken to know what impact the chosen number of rays has on the accuracy of the five indicators - sky view factor, aspect ratio, building surface fraction, impervious surface fraction, and height of roughness elements (Fig. 11). Five different number of rays (ie. different angular abscissa values) were chosen: 16, 32, 64, 128, and 256. It is clear that, whatever the terrain chosen among the three, the increase in the number of rays does not significantly modify the values of all the indicators. In the following case studies, we arbitrarily set the number of rays at 64 (nRays). This angular abscissa value is a good compromise, since it allows an infra-decametric accuracy for a radius of $100 \mathrm{~m}$ while preserving a reasonable computation time, as we have been able to verify empirically in previous studies. 

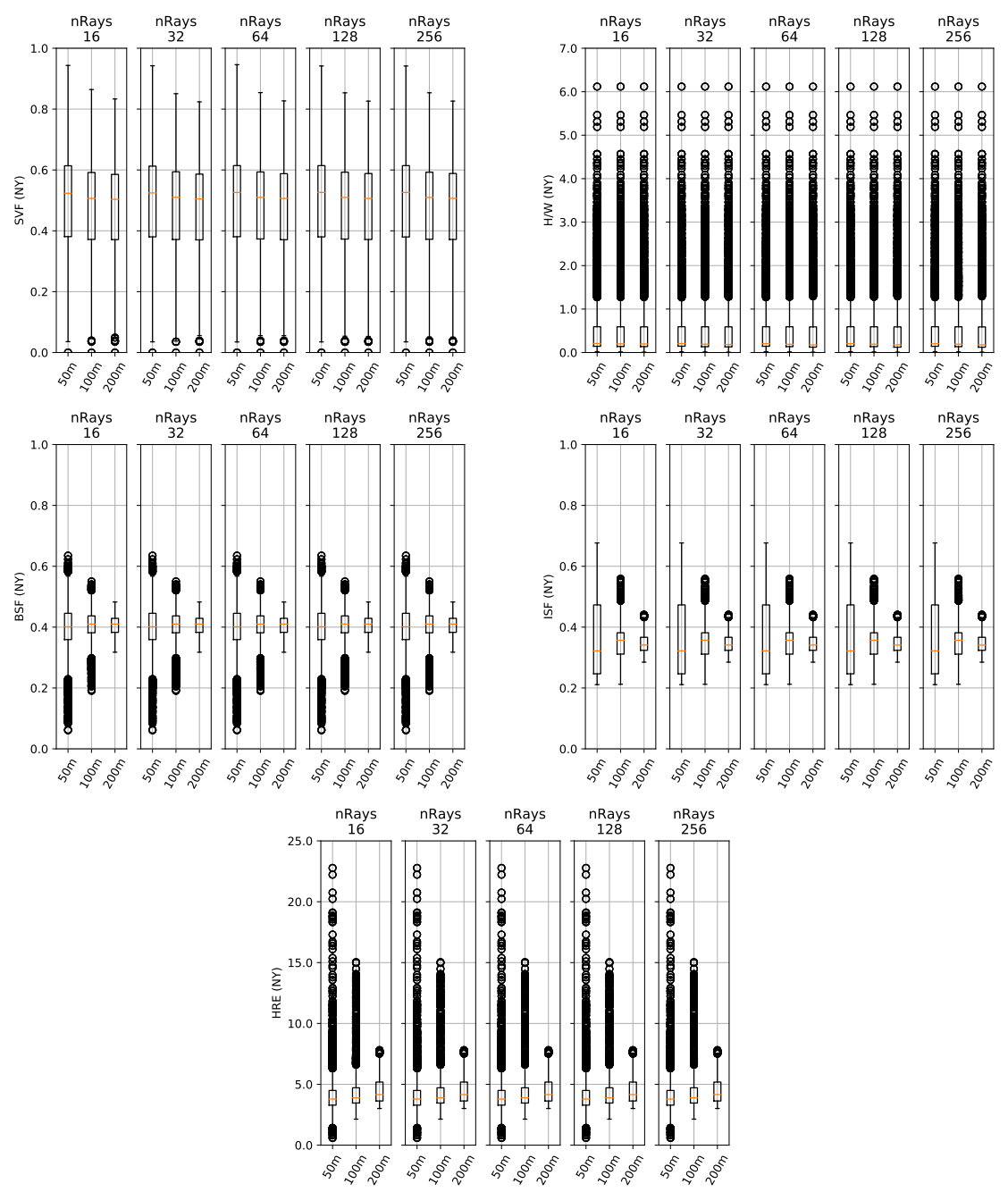

Fig. 11: Influence of the number of rays on SVF, H/W, BSF, ISF, and HRE indicators, the ray length being fixed at $100 \mathrm{~m}$ (Borough Park, New York).

\subsection{LCZ - Delaunay Triangulation}

The first figure (Fig. 12a) shows the identified LCZs on a district of New York. First of all, we can note that a lot of sensors are not identified within any LCZ. Second, we observe that the main LCZs are LCZ 2, 3 and 5 corresponding to compact high-rise, compact low-rise and open mid-rise. These first two LCZs are found both in the major and minor classes. Some sensors, in green, are identified as belonging to the open mid rise and low rise and very few, in blue, seem to belong to the lightweight low-rise class.

The second district located in Nantes (Royale) is mainly characterized by the LCZ 3 and 6 (Fig. 12b). Compared to Borough Park, this French district is less dense, with lower buildings, which is the reason why the LCZ found is lower than for Borough Park. Some outlying sensors are identified as LCZ 3 and 5. Finally, this district is mainly compact low-rise 
and open mid-rise.

The Méthode district of Nantes has a lot of non-identified sensors, because they do not match within any of the LCZs proposed by (I. D. Stewart and T. R. Oke 2012) (Fig. 12c). Close to the higher buildings, LCZ 3 is found and LCZ 5 and 6 are found. Most of the minors are identified as LCZ 6. This shows that Méthode district is less compact and low-rise compared to the Royale district.

Not all nodes of the districts studied in this paper are associated to a LCZ. There is a clear difference between the typical urban configuration of a North American district with contemporary architecture, where only $24 \%$ of the nodes do not match to a LCZ and the classic European architectural district of Royale, where $34.7 \%$ of the nodes have no associated LCZ. Finally for Méthode, a residential area of intermediate density, the worst case, $83.7 \%$ of the nodes do not meet the requirements to fit to a LCZ. These results show clearly that the LCZ classification is better suited to the dense and planned urban districts than to the classical or diffused ones. 


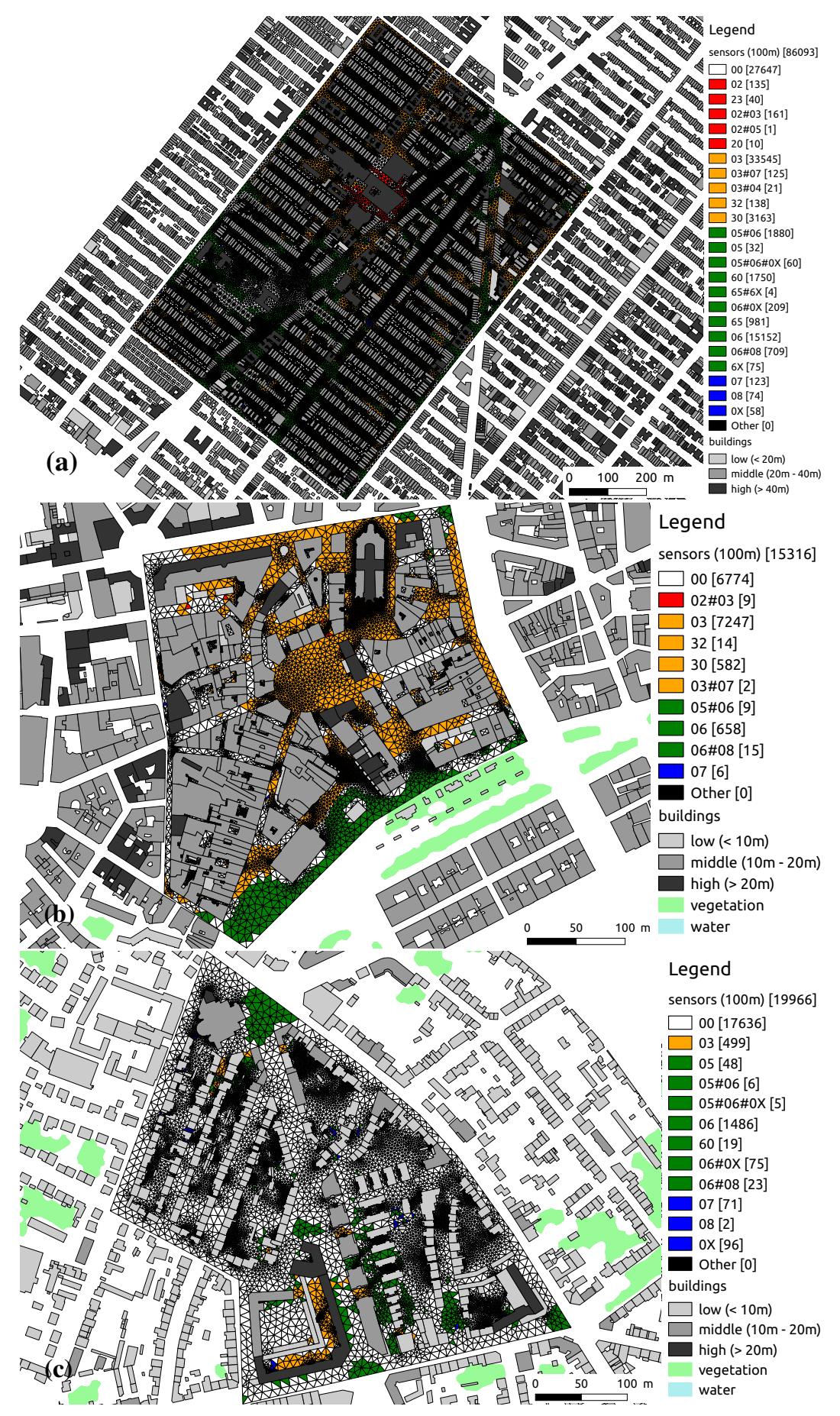

Fig. 12: Determination of LCZs for the three case studies (Delaunay Triangulation, rayLen $=100 \mathrm{~m}, \mathrm{nRays}=64$ ): (a) New York (Borough Park). (b) Nantes, France (Royale district). (c) Nantes, France (Méthode district). 


\subsection{LCZ - skeleton}

The main observations for all districts are similar to the ones obtained

527 with the Delaunay triangulation method (Fig. 13). 


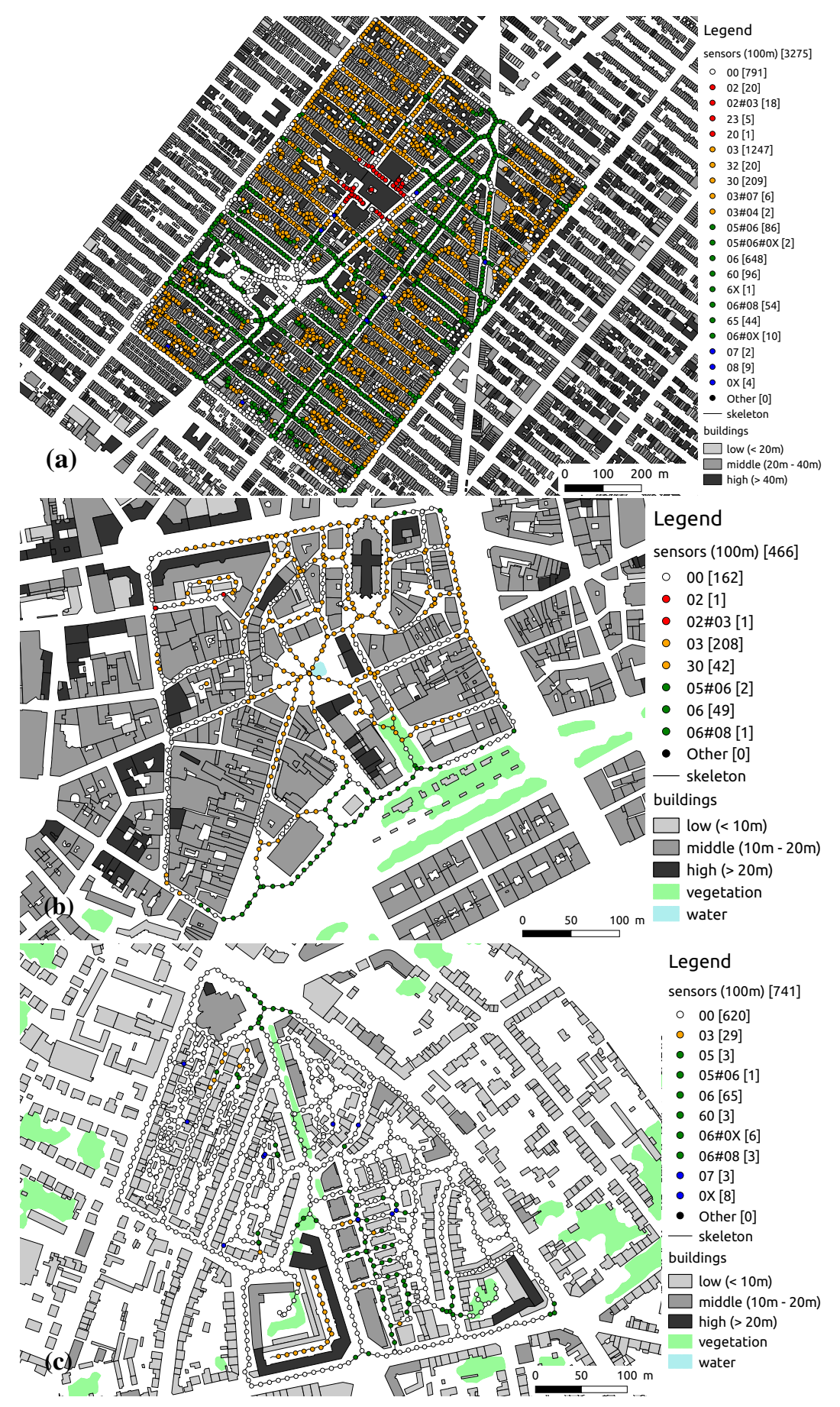

Fig. 13: Determination of LCZs for the three case studies (Skeleton, rayLen $=100 \mathrm{~m}, \mathrm{nRays}=64)$ : (a) New York (Borough Park). (b) Nantes, France (Royale district). (c) Nantes, France (Méthode district). 
a district of New York (Fig. 13a). Again, the main LCZs are LCZ 2, 3 and 5, corresponding to compact high-rise and compact low-rise.

The second district located in Nantes (Royale) is again mainly characterized by the LCZ 3 and 6 (Fig. 13b) and the same outlying sensors.

The Méthode district of Nantes has again a lot of non-identified sensors because they do not match into any of the LCZs proposed by (I. D. Stewart and T. R. Oke 2012) (Fig. 13c) and close to the higher buildings, LCZ 3 is found and LCZ 5 and 6 are found too.

\subsection{Verification of the LCZ simulated}

A local climate zone is defined as an area which presents uniform features as for example in terms of urban morphology, land use, and a characteristic screen-height temperature regime. This is why we have first compared the LCZ obtained in this paper to the air temperature measured by (Bernard, Musy, et al. 2017). First, we have observed a distinct air temperature difference between Royale district and Méthode district. (Bernard, Musy, et al. 2017) observed an UHI amplitude of $2.5^{\circ} \mathrm{C}$ in the Royale district and an amplitude of $1.5^{\circ} \mathrm{C}$ only for Méthode district. This means that between Royale district and Méthode district the air temperature difference is of one degree. This confirms our results: the two districts do not belong to the same LCZ as their air temperature regime is not the same.

Secondly, we have compared the LCZ obtained on Royale district and Méthode district to the LCZ map of WUDAPT community ${ }^{6}$. The tendencies are verified: Royale disctrict is classified as LCZ 3 by WUDAPT and corresponds to the major LCZ found in this paper. Méthode district is classified as LCZ 6 by WUDAPT and corresponds to the major LCZ found in this paper. This last verification is very global as the WUDAPT LCZ map is only one hundred meter per one hundred meter large. Unfortunately, this resolution is not accurate enough to validate the minor LCZ found in this paper. To improve the validation at a smaller scale, air temperature sensors should have been placed in the urban open spaces of Royale and Méthode districts. This could not be done in the context of this study paper due to the lack of funding, but should be done in future.

\subsection{About calculation times}

We performed all the simulations on a Linux Ubuntu 14.04 LTS computer, equipped with Intel ${ }^{\circledR}$ Xeon ${ }^{\circledR}$ Processor E3-1246 v3 (Quad Core HT, $3.50 \mathrm{GHz}, 8 \mathrm{MB}$ ) and with $16 \mathrm{Go} 1600 \mathrm{MHz}$ DDR3 Non-ECC SDRAM. The version of the QGIS software used is 2.18.11, the version of the GMSH software used to mesh the study space is 2.8.3.

For the estimation of calculation times, we take care to clearly distinguish pre-processing (by Delaunay triangulation or skeletonization), processing (evaluation of indicators and LCZ in each sensor), and post-processing (matching of the two methods, mapping rendering). The calculation times given in Table 3 correspond only to the processing times, excluding preand post-processing.

${ }^{6}$ See the map available at https://geopedia.world/\#T4_L107_x-168925.83251023944 y5992280.832416391_s10_b17 (Accessed February 2019). 
Table 3: Calculation times (hh:mm:ss).

\begin{tabular}{|c|c|c|c|c|c|}
\hline \multirow{2}{*}{$\begin{array}{c}\text { Mesh } \\
\text { type }\end{array}$} & \multirow{2}{*}{ District } & \multirow{2}{*}{$\begin{array}{l}\text { Number } \\
\text { of sensors }\end{array}$} & \multicolumn{3}{|c|}{ Ray lengths (m) } \\
\hline & & & 50 & 100 & 200 \\
\hline \multirow{5}{*}{$\begin{array}{c}\text { Triangulated } \\
\text { Irregular } \\
\text { Network }\end{array}$} & New York & & & & \\
\hline & Borough Park & 86,093 & 03:44:42 & 05:07:21 & 14:13:02 \\
\hline & Nantes & & & & \\
\hline & $\begin{array}{l}\text { Royale district } \\
\text { Nantes }\end{array}$ & 15,316 & 00:20:19 & 00:48:44 & 02:15:12 \\
\hline & Méthode district & 19,966 & $00: 20: 46$ & $00: 52: 51$ & 02:30:59 \\
\hline \multirow{5}{*}{ Skeleton } & New York & & & & \\
\hline & Borough Park & 3275 & 00:07:39 & $00: 12: 50$ & 00:31:19 \\
\hline & $\begin{array}{c}\text { Nantes } \\
\text { Rovale district }\end{array}$ & 466 & $00 \cdot 00 \cdot 37$ & $00 \cdot 01 \cdot 21$ & $00 \cdot 03 \cdot 54$ \\
\hline & Nantes & & & & \\
\hline & Méthode district & 741 & 00:00:46 & 00:01:52 & 00:05:52 \\
\hline
\end{tabular}

As an indication, we can specify that the pre-processing time for Borough Park (New York) is 00:37:59 with the Skeletonization and 00:04:46 with the Triangulation. The pre-processing time for the Royale District (Nantes) is 00:00:26 (Skeletonization) and 00:00:13 (Triangulation). The preprocessing time for Méthode District (Nantes) is 00:00:28 (Skeletonization) and 00:00:19 (Triangulation). The pre-processing time for Skeletonization is always longer than for the triangulation as seen above, but it is for the processing times Table 3 that the Skeletonization becomes very interesting compared to the Delaunay triangulation. For example, for New York and with a ray length of $100 \mathrm{~m}$ the skeleton needs $\leq 13 \mathrm{~min}$, whereas the triangulated network needs more than five hours to process.

\section{Discussion}

\subsection{LCZs correlation}

The figures below show the correlation between the results obtained with the Delaunay triangulation and the skeletonization (Fig. 14). The confidence interval is set to one when results are entirely correlated, and set to zero when no correlation is found as explained before.

For New York, 2817 sensors out of $3270(86.1 \%)$ have a very high confidence interval and 447 sensors out of $3270(13.7 \%)$ have a good confidence.

For the Royale district, 359 out of 465 sensors have a high confidence interval, which represents $(77.2 \%)$ of high confident sensors.

Third, the Méthode District presents 654 sensors out of the 739 total sensors, which have a confidence between 0.82 and 1 , which represents $88.5 \%$.

To conclude, most of the sensors of the three districts show a high confidence between 0.82 and 1 . This means that the skeleton is representative of the district and can be applied to predict the local climate zones. 


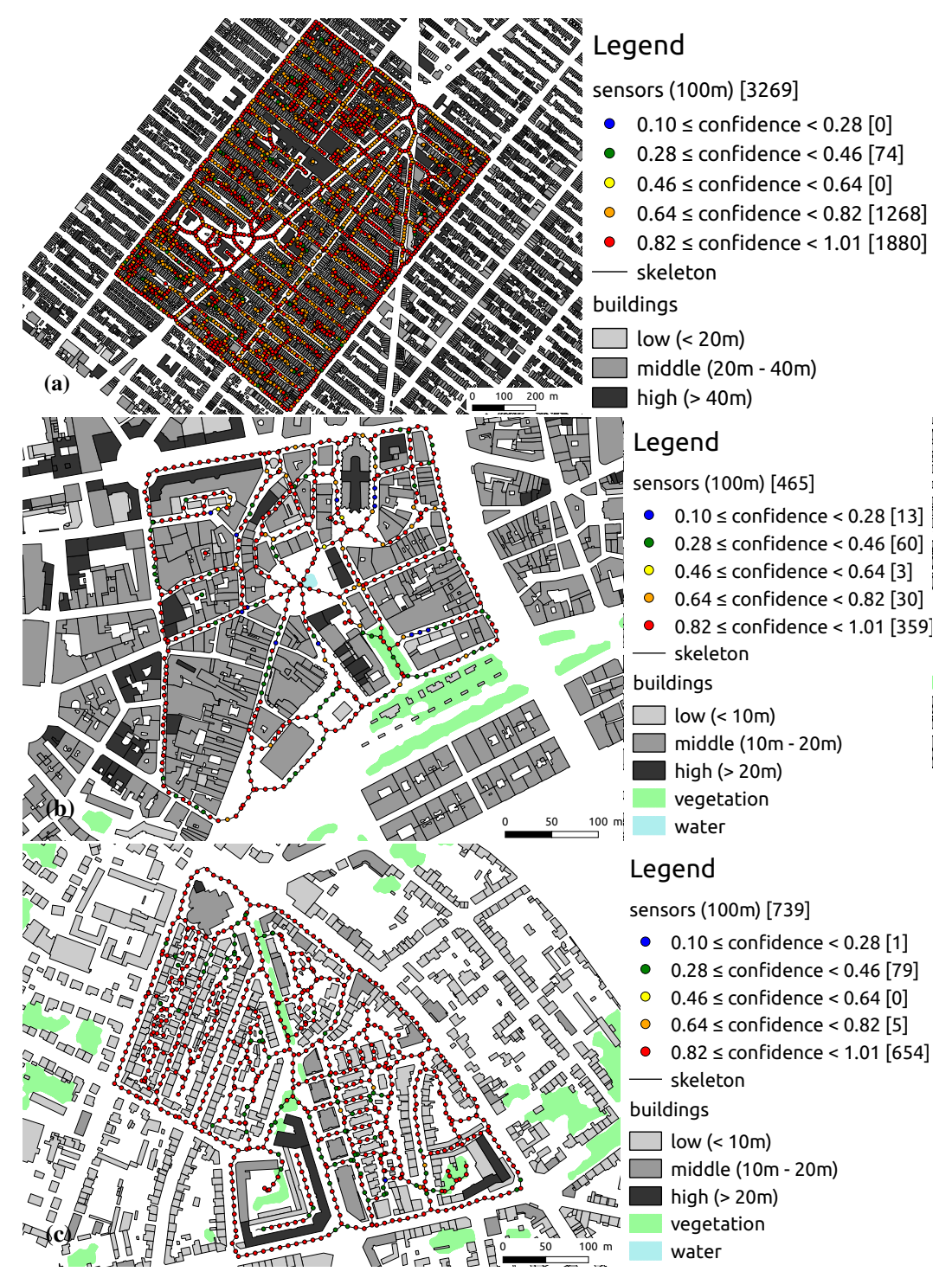

Fig. 14: LCZs correlation: Delaunay Triangulation vs. Skeleton, for the three case studies (rayLen=100m): (a) New York (Borough Park). (b) Nantes, France (Royale district). (c) Nantes, France (Méthode district).

\subsection{Indeterminacy of LCZs: Zoom in nodata values}

The street of "rue d'Orléans" in Nantes opens to the west on Place Royale and to the east on the courtyard named "50 otages" (Fig. 15a). This street is a pedestrian zone made up of a homogeneous group of buildings of classic style. Unlike the sensors at its ends - which fall exclusively under LCZ 3 - the 24 "central" sensors on this street do not fit into any LCZ (white facets). This indetermination can be attributed to two of the five indicators allowing the identification of the associated LCZ. Therefore, if, for these 24 sensors, the BSF, ISF and HRE come under LCZ 3, a contrario, on this 


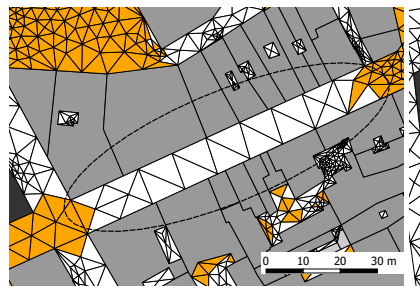

zone, the values of SVF spread between $17.31 \%$ and $19.37 \%$, and those of H/W spread between 1.66 and 1.84. According to (I. D. Stewart and T. R. Oke 2012), the thresholds for the SVF and H/W indicators in LCZ 3 are set between $20 \%$ and $60 \%$ on the one hand, and 0.75 and 1.5 on the other. We conclude that, for these thresholds and for our indicator calculation method, this street is too "boxed/canyon" to fit into LCZ 3.

The 27 sensors located in the lower part of the "rue du Chapeau Rouge" are in a situation of indeterminacy (Fig. 15b), while the sensors surrounding them are registered in LCZ 2 or 3. To explain this indeterminacy, we analyzed the values of all the indicators of each of these sensors. In all cases, it appears that, in all cases, the SVF indicator places the sensors in LCZ 2 as in LCZ 3, the indicator places the sensors in LCZ 2 as in LCZ 3 (but also in LCZ 1), the ISF indicator places the sensors in LCZ 3 (but also in LCZ 6 and 10), the HRE indicator places the sensors in LCZ 2 (but also in LCZ 5 and 10). In addition, in a majority of cases, the $\mathrm{h} / \mathrm{w}$ indicator places a majority of the sensors in LCZ 5 or 6 (but in no case in LCZ 2 or LCZ 3). If three indicators (SVF, BSF, and HRE) place all the sensors in LCZ 2 and three indicators (SVF, BSF and ISF) place them in LCZ 3, one can notice that there is no LCZ for these sensors that has at least 4 of the 5 indicators. This lack justifies the indeterminacy we see when we read the map.

As in the case of "rue d'Orléans", the 24 sensors on "rue des Vieilles Douves" (Fig. 15c) - which opens to the west northwest into the Place Royale - are undetermined. This indetermination is all the more surprising as, on both sides, the sensors are exclusively under LCZ 3. A more precise study allows us to attribute this indetermination only to the SVF and $\mathrm{h} / \mathrm{w}$ indicators (BSF, ISF, and HRE being perfectly in line with LCZ 3). Indeed, for these sensors, the SVF values spread between $6.23 \%$ and $19.79 \%$ and those of $\mathrm{h} / \mathrm{w}$ spread between 1.58 and 3.83 . We are well below $20 \%$ in the first case, and above 1.5 in the second. More than "rue d'Orléans", "rue des Vieilles Douves" is far too "boxed/canyon" to fit into LCZ 3.

Fig. 15: Three cases of indeterminacy: (a) rue d'Orléans. (b) rue du Chapeau Rouge.(c) rue des Vieilles Douves.

We can conclude that the intervals proposed by (I. D. Stewart and T. R. Oke 2012) are not covering perfectly all the potential indicator values as seen here.

\section{Conclusion and outlooks}

This paper presents a methodology to apply local climate zones classification on local and micro scales. Among seven indicators proposed by (I. D. Stewart and T. R. Oke 2012), corresponding to geometric and surface cover properties, five have been implemented successfully in this paper. 
Two indicators among these five have been improved. A SVF definition adapted from (Bernard, Bocher, et al. 2018) has been implemented in our paper. The aspect ratio is calculated differently either for canyon streets or squares. This distinction is related to the lack of a clear main direction for open spaces that are not canyons.

The advantage of the proposed method is that the generation of LCZs is repeatable elsewhere providing that the standard geographical information of the city is given. Another advantage of the proposed method is that it is robust: the major and minor LCZs found follow a deterministic algorithm transposable elsewhere.

After a sensitivity analysis on the radius length, the results on several districts showed that the indicators could be calculated for different methods of dividing the space: the Delaunay triangulation and the Skeletonization. Results obtained with Skeletonization are strongly correlated to Delaunay's, which means than skeletonization could replace the Delaunay triangulation. Skeletonization showed also the advantage to pull down calculation time. The major LCZs found on the districts of Nantes are compared to previous obtained UHI measures and to WUDAPT portal. These comparisons confirm that the major LCZs found in this paper are coherent.

Finally, we observe that some sensors are not identified within any LCZ, or aligned poorly with a LCZ. A first reason is, that there is no LCZ for these sensors that validates at least 4 of the 5 indicators. For another case, three indicators come into a LCZ but the two remaining indicators do not fit into any LCZ. This means that the local climate zones proposed by (I. D. Stewart and T. R. Oke 2012) do not cover all the urban fabrics as for example the more classic architecture and is more suited to contemporary urban forms as already highlighted by (Leconte et al. 2015). In the future, the classification propose by (I. D. Stewart and T. R. Oke 2012) needs to be improved, so that more urban fabrics can be identified and classified into a local climate zone. We propose to continue working on LCZ subclasses as some authors have already done (Kotharkar and Bagade 2018; Leconte et al. 2015). But the main challenge is still to identify the main urban fabrics that do not fit into the LCZ proposed by (I. D. Stewart and T. R. Oke 2012) as for example some regions of the city of Nancy which present important inhomogeneities in surface structure cover, fabric, etc. (Leconte et al. 2015). Once a set of non-identified regions are put aside we propose to measure the air temperature within these regions and identify the vulnerability of these regions to the UHI magnitude. Then, we propose to retrieve the urban indicators representing these regions. After that, we propose to add these new LCZs (characterized by the urban indicators representing them) to the classical LCZ scale (I. D. Stewart and T. R. Oke 2012). Finally the modified LCZ scale should improve the estimation of the UHI magnitude for heterogeneous and compact cities. Moreover, the albedo needs to be identified and considered when looking for the LCZ. The consideration of the albedo is proposed by (I. D. Stewart and T. R. Oke 2012) but has not been calculated in our paper, which should be done in the future. The identification of the albedo at a district scale is challenging, though some authors found a simpler method to evaluate the urban albedo at a block scale (Bernabé et al. 2015).

A future work will be to obtain the air temperature in the districts presented in this paper using mobile measurements to confirm the major and minor LCZs found. This validation will be done on a smaller scale, compared to the global verification done in this paper. 


\title{
Acknowledgments
}

\section{Conflict of interests}

The authors declare no conflict of interest.

\author{
Abbreviations \\ The following abbreviations are used in this manuscript: \\ BSF: Building Surface Fraction \\ DT: Delaunay Triangulation \\ HRE: Height of Roughness Elements \\ LCZ: Local climate zone \\ PSF: Pervious Surface Fraction \\ ROI: Region Of Interest \\ SKEL: Skeleton \\ SVF: Sky View Factor \\ UHI: Urban Heat Island \\ WUDAPT: World Urban Database and Access Portal Tools
}

\section{References}

Azam, Marie-Hélène et al. (2018). "A pavement-watering thermal model for SOLENE-microclimat: Development and evaluation". In: Urban Climate vol. 25, pp. 22-36. ISSN: 22120955. DOI: 10 . 1016/ j . uclim . 2018 . 04 . 005. URL: https : / / linkinghub . elsevier.com/retrieve/pii/S2212095518301159.

Bechtel, Benjamin et al. (2017). "Quality of Crowdsourced data on urban morphology - The human influence experiment (HUMINEX)". In: Urban Science 1.2, p. 15. ISSN: 2413-8851. DOI: 10 . 3390 / urbansci1020015. URL: http : / / ww . mdpi . com/2413 - 8851 / $1 / 2 / 15$.

Benedikt, Michael L. (1979). “To take hold of space: isovists and isovist fields". In: Environment and Planning B: Planning and Design 6.1, pp. 47-65. DOI: 10.1068/b060047. URL: https://journals . sagepub.com/doi/abs/10.1068/b060047.

Bernabé, Anne et al. (2015). "Radiative properties of the urban fabric derived from surface form analysis: A simplified solar balance model". In: Solar Energy 122, pp. 156-168. ISSN: 0038092X. DOI: $10.1016 / j$. solener . 2015 . 08 . 031. URL: https : / / linkinghub.elsevier.com/retrieve/pii/S0038092X15004673. 
Bernard, Jérémy, Erwan Bocher, et al. (2018). "Sky view factor calculation in urban context: Computational performance and accuracy analysis of two open and free GIS tools". In: Climate 6.3, p. 60. ISSN: 2225-1154. DOI: 10 . $3390 /$ cli6030060. URL: http : //www . mdpi.com/2225-1154/6/3/60.

Bernard, Jérémy, Marjorie Musy, et al. (2017). “Urban heat island temporal and spatial variations: Empirical modeling from geographical and meteorological data". In: Building and Environment 125, pp. 423-438. ISSN: 03601323. DOI: 10.1016 / j . buildenv . 2017 .08 . 009. URL: https : / / linkinghub . elsevier . com / retrieve/pii/S0360132317303554.

Bernard, Jérémy, Auline Rodler, et al. (2018). “How to design a park and its surrounding urban morphology to optimize the spreading of cool air?" In: Climate 6.1, p. 10. ISSN: 2225-1154. DOI: 10 . 3390 / cli6010010. URL: http : / / www . mdpi . com / 2225 1154/6/1/10.

Bocher, Erwan et al. (2018). "A geoprocessing framework to compute urban indicators: The MApUCE tools chain". In: Urban Climate 24.January, pp. 153-174. ISSN: 22120955. DOI: 10.1016/j .uclim . 2018.01 .008$.

Fenner, Daniel et al. (2017). “Intra and inter 'local climate zone' variability of air temperature as observed by crowdsourced citizen weather stations in Berlin, Germany". In: Meteorologische Zeitschrift 26.5, pp. 525-547. ISSN: 16101227. DOI: 10.1127 /metz / 2017 / 0861.

Gál, Tamás, F. Lindberg, and J. Unger (2009). "Computing continuous sky view factors using 3D urban raster and vector databases: Comparison and application to urban climate". In: Theoretical and Applied Climatology 95.1-2, pp. 111-123. ISSN: 0177-798X. DOI: 10 . 1007 / s00704 $007-0362$ - 9. URL: http : / / link . springer . com / 10 . 1007 / s00704-007-0362-9.

Geletič, Jan and Michal Lehnert (2016). "GIS-based delineation of local climate zones: The case of medium-sized central European cities". In: Moravian Geographical Reports 24.3, pp. 2-12. ISSN: 12108812. DOI: 10.1515/mgr-2016-0012. URL: http://content . sciendo.com/view/journals/mgr/24/3/article-p2.xml.

Grimmond, C. S. B. et al. (2010). “The International Urban Energy Balance Models Comparison Project: First Results from Phase 1". In: Journal of Applied Meteorology and Climatology 49.6, pp. 12681292. ISSN: 1558-8424. DOI: 10 . 1175 / 2010JAMC2354 . 1. URL: http://journals . ametsoc.org/doi/abs/10.1175/2010JAMC2354. 1.

Johnson, Glenn T. and Ian D. Watson (1984). “The Determination of View-Factors in Urban Canyons". In: Journal of Climate and Applied Meteorology 23.2, pp. 329-335. ISSN: 0733-3021. DOI: 10.1175/1520-0450(1984) 023<0329: TDOVFI>2.0.C0;2. URL: http: //journals . ametsoc . org / doi / abs / 10 . 1175 / 1520 - 0450\% 7B \% \% 7D281984\% 7B \% $\% 7 \mathrm{D} 29023 \%$ 7B \% \% 7D3C0329\% 7B \% \% 7D3ATDOVFI \% 7B\% \%7D3E2 . 0 . $\mathrm{CO} \% 7 \mathrm{~B} \%$ \% $\mathrm{D} 3 \mathrm{~B} 2$. 
Kotharkar, Rajashree and Anurag Bagade (2018). "Evaluating urban heat island in the critical local climate zones of an Indian city". In: Landscape and Urban Planning 169, pp. 92-104. ISSN: 01692046. DOI: $10.1016 / \mathrm{j}$. landurbplan . 2017 . 08 . 009. URL: https : //content. sciendo.com/view/journals/mgr/24/3/ article-p2.xml.

Lai, Li Wei (2018). “The influence of urban heat island phenomenon on PM concentration: An observation study during the summer half-year in metropolitan Taipei, Taiwan". In: Theoretical and Applied Climatology 131.1-2, pp. 227-243. ISSN: 14344483. DOI: 10.1007 / s00704016-1975-7.

Leconte, Francois et al. (2015). “Using local climate zone scheme for UHI assessment: Evaluation of the method using mobile measurements". In: Building and Environment 83, pp. 39-49. ISSN: 03601323. DOI: $10.1016 / \mathrm{j}$. buildenv . 2014.05.005.

Lelovics, E et al. (2014). “Design of an urban monitoring network based on local climate zone mapping and temperature pattern modelling". In: Climate Research 60.1, pp. 51-62. ISSN: 0936-577X. DOI: $10.3354 / \mathrm{cr} 01220$.

Mills, Gerald (2007). "Cities as agents of global change". In: International Journal of Climatology 27.14, pp. 1849-1857. ISSN: 08998418. DOI: $10.1002 /$ joc. 1604. URL: http://doi.wiley.com/10.1002/joc.1604.

Morille, Benjamin and Marjorie Musy (2017). "Comparison of the impact of three climate adaptation strategies on summer thermal comfort - cases study in Lyon, France". In: Procedia Environmental Sciences 38, pp. 619-626. ISSN: 18780296. DOI: 10.1016/j.proenv. 2017. 03.141. URL: http: //linkinghub. elsevier .com/retrieve/ pii/S1878029617301457.

Musy, Marjorie, Laurent Malys, and Christian Inard (2017). “Assessment of direct and indirect impacts of vegetation on building comfort: A comparative study of lawns, green walls and green roofs". In: Procedia Environmental Sciences 38, pp. 603610. ISSN: 18780296. DOI: $10.1016 / \mathrm{j}$. proenv . 2017 .03 . 134. URL: http : / / linkinghub . elsevier . com / retrieve / pii / S187802961730138X.

Musy, Marjorie, Laurent Malys, Benjamin Morille, et al. (2015). “The use of SOLENE-microclimat model to assess adaptation strategies at the district scale". In: Urban Climate 14.March 2016, pp. 213223. ISSN: 22120955. DOI: $10.1016 / \mathrm{j} \cdot \mathrm{ucl} \mathrm{im} .2015 .07 .004$. URL: http : / / linkinghub . elsevier . com / retrieve / pii / S2212095515300109.

Oke, Tim R. (2006). "Towards better scientific communication in urban climate". In: Theoretical and Applied Climatology. ISSN: 14344483. DOI: $10.1007 / \mathrm{s} 00704-005-0153-0$.

Oke, T.R. (1987). Boundary Layer Climates, 2nd edition. Rootledge. ISBN: 9780415043199.

- (1988). "Street design and urban canopy layer climate". In: Energy and Buildings 11.1-3, pp. 103-113. ISSN: 03787788. DOI: 10.1016/0378-7788(88) 90026-6. URL: http://linkinghub. elsevier .com/retrieve/ pii/0378778888900266. 
Openshaw, Stan (1983). “The modifiable areal unit problem". In: CATMOG - Concepts and Techniques in Modern Geography vol. 38, p. 41. URL: http://www.getcited.org/pub/102412488.

Perera, N.G.R and R. Emmanuel (2018). "A "local climate zone" based approach to urban planning in Colombo, Sri Lanka". In: Urban Climate 23, pp. 188-203. ISSN: 22120955. DOI: 10 . 1016/ j.uclim.2016.11.006.

Plumejeaud-Perreau, Christine et al. (2015). “Building local climate zones by using socio-economic and topographic vectorial databases". In: ICUC9, Toulouse, France (20-24 July).

Quanz, Justus A et al. (2018). "Micro-scale variability of air temperature within a local climate zone in Berlin, Germany, during summer". In: Climate 6.1, p. 5. ISSN: 2225-1154. DOI: 10 . $3390 /$ cli6010005. URL: http://www. mdpi.com/2225-1154/6/1/5.

Salvati, Agnese, Helena Coch Roura, and Carlo Cecere (2015). "Urban morphology and energy performance: The direct and indirect contribution in Mediterranean climate". In: PLEA 2015 Architecture in (R)Evolution - 31st Inte pp. 1-8.

Santamouris, M. et al. (2017). "Passive and active cooling for the outdoor built environment - analysis and assessment of the cooling potential of mitigation technologies using performance data from large scale projects". In: Solar Energy 2017, pp. 154, 14-33.

Sarradin, François et al. (2007). "Comparing sky shape skeletons for the analysis of visual dynamics along routes". In: Environment and Planning B: Planning and Desi 34.5, pp. 840-857. ISSN: 0265-8135. DOI: 10 . 1068/b32143. URL: http://journals. sagepub.com/doi/10.1068/b32143.

Souza, Léa C.L., Daniel S. Rodrigues, and José F.G. Mendes (2003). "Sky view factors estimation using a 3D-GIS extension". In: 8th International IBPSA Conference, pp. 1227-1234. URL: http://hdl.handle.net/1822/2206.

Stewart, I. D. and T. R. Oke (2012). “Local climate zones for urban temperature studies". In: American Meteorological Society.

Stewart, Iain D., T. R. Oke, and E. Scott Krayenhoff (2014). "Evaluation of the 'local climate zone' scheme using temperature observations and model simulations". In: International Journal of Climatology 34.4, pp. 1062-1080. ISSN: 08998418. DOI: 10.1002/joc.3746.

Steyn, D.G. (1980). "The calculation of view factors from fisheyelens photographs: Research note". In: Atmosphere-Ocean 18.3,

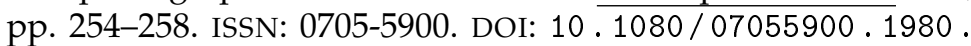
9649091.

Teller, Jacques and S. Azar (2001). “Townscope II-A computer system to support solar access decision-making". In: Solar Energy 70.3, pp. 187-200. ISSN: 0038092X. DOI: 10.1016/S0038-092X(00) 00097-9. URL: http://linkinghub. elsevier.com/retrieve/ $\mathrm{pii} / \mathrm{S} 0038092 \times 00000979$.

$\mathrm{Yu}$, Bingfeng et al. (2008). "Study on the influence of albedo on building heat environment in a year-round". In: Energy and Buildings 40, pp. 945-951. 